\title{
Electro-thermal Modeling of Permanent Magnet Synchronous Motor
}

\author{
Souhir Tounsi \\ National School of Electronics and Telecommunications of Sfax, Sfax University, SETIT Research Unit, Sfax, Tunisia \\ Email address: \\ souhir.tounsi@enetcom.rnu.tn \\ To cite this article: \\ Souhir Tounsi. Electro-thermal Modeling of Permanent Magnet Synchronous Motor. International Journal of Electrical Components and \\ Energy Conversion. Vol. 1, No. 2, 2015, pp. 63-68. doi: 10.11648/j.ijecec.20150102.13
}

\begin{abstract}
In this paper, we present a methodology for electro-thermal characterization of a permanent magnet synchronous motor (PMSM). This modeling approach is in the aim to evaluating the different temperatures in different active parts of the motor, to choose the type and characteristics of the cooling system to use. This study led to the selection of a cooling system by water forced convection.
\end{abstract}

Keywords: Electro-Thermal, Modeling, Nodal Method, Simulation, Permanents Magnets Motor, Cooling System

\section{Introduction}

The main objective of the electro-thermal modeling of thermal stresses is to respect the good working of the electric motor. In fact, exceeding the melting temperature of the coils insulation set at $100^{\circ} \mathrm{C}$ leads to the deterioration of the coils and subsequently damages the motor [1], [2]. In addition, knowledge of different temperatures in the active areas of the engine allows firstly to take into account the change of the $\mathrm{B}-\mathrm{H}$ magnets characteristic (critical temperature is not to exceed $200^{\circ} \mathrm{C}$ for Sm-Co magnet), and secondly the change in resistance phases of electric motor, strongly influencing the electrical, magnetic and mechanical behavior of engine [3]. This knowledge of temperatures determines the nature and power of the cooling system to integrate in the engine.

We set a goal to not exceed the limits of the following temperatures [1], [2], [3]:

- $200^{\circ} \mathrm{C}$ for permanent magnets (Sm-Co).

- $100^{\circ} \mathrm{C}$ for the insulator coil.

This survey must succeed to the choice the least expensive cooling system.

\section{Choice of Modeling Approach}

Conventional analytical methods, describes heat transfer with an acceptable complexity. However these methods require precise knowledge of many coefficients (thermal conductivity, heat transfer coefficient, and emissivity) that's often difficult to obtain.

Finite elements methods require an important memory resources and computation time. They are therefore not compatible with our approach should allow to model a magnetic component in its environment ie part of a chain of power. In addition, the model developed should make account of all the phenomena involved in a magnetic component (electric phenomena, magnetic and thermal).

The nodal method provides better accuracy compromised results and simulation time. It is therefore compatible to optimization approaches such as the performance of electric vehicle. It seems however best suited to our concerns and lends itself well to an experimental approach. The component to be modelled is divided into insulated areas interconnected by a thermal resistance, the center of a zone is called node. A thermal capacity and a heat source are associated with each zone. A system of differential equations is obtained by writing the heat balance at the various nodes. A first approximation is to consider thermal resistance as constant (for better accuracy thermal resistances can be modelled using analytical relations).

For the components of our synchronous motor, the equivalent circuit is limited to a few resistors and capacitors whose values can be obtained by calculation. This method meets our specifications [4], [5], [6].

\section{Nodal Thermal Model of PMSM}

The system to be modelled is a permanent magnet synchronous motor (PMSM) with axial flux (Figure 1). 


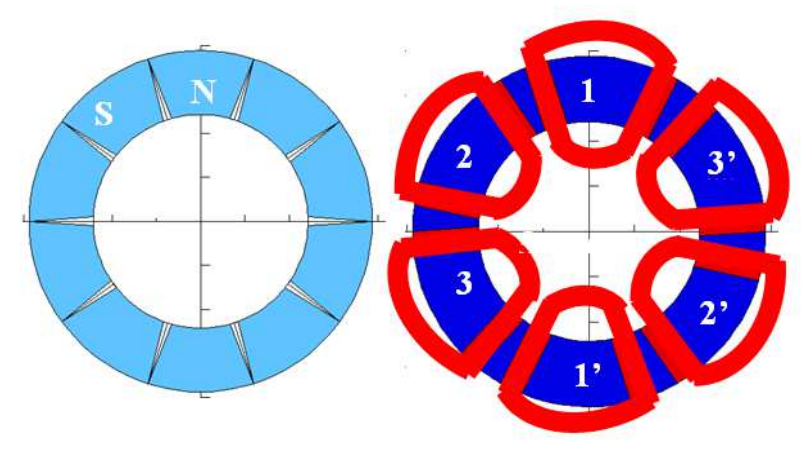

Figure 1. PMSM structure.

The 3 D structure of PMSM is illustrated by figure 2 .

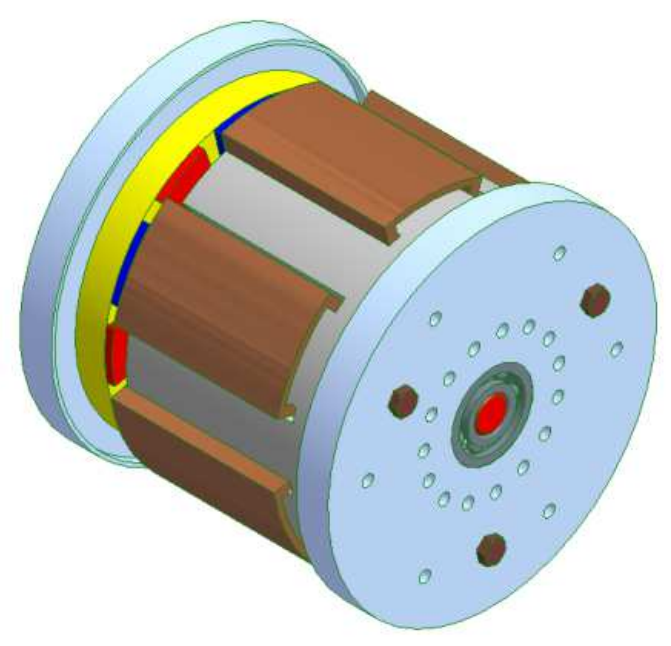

Figure 2. 3 D structure of PMSM.

The dimensioning model of this structure is detailed in [7].

\subsection{Assumptions Used for Modeling}

We recall firstly our assumptions about thermal modeling of magnetic components to justify the principles of selected measures that lead to the measurement of average temperatures. Temperatures are assumed uniform in the material and in the different coils.

We consider an ambient temperature of $40^{\circ} \mathrm{C}$ and we assume a maximum permissible temperature rise of $100^{\circ} \mathrm{C}$ for the insulation. This warming-up is determined by the temperature holding of the conductors and the slots bottom insulators. At the same way, the maximum warming-up of the magnets (Sm-Co) must be taken in account and we admit a warming-up of the order of $200^{\circ} \mathrm{C}$. In the context of our model, we consider only perfect contacts, and their conduction resistances are low and broken into account in the thermal model of the PMSM [8], [9], [10].

The heat exchange is assumed in the axial direction, because the length of the structure in this direction is much lower than that in the radial direction, in addition heat exchange sections perpendicular to the axis of the motor is much greater than those radials [8], [9], [10].

\subsection{Heat transfer in the PMSM}

Heat transfer in the PMSM is illustrated by the Figure 3:

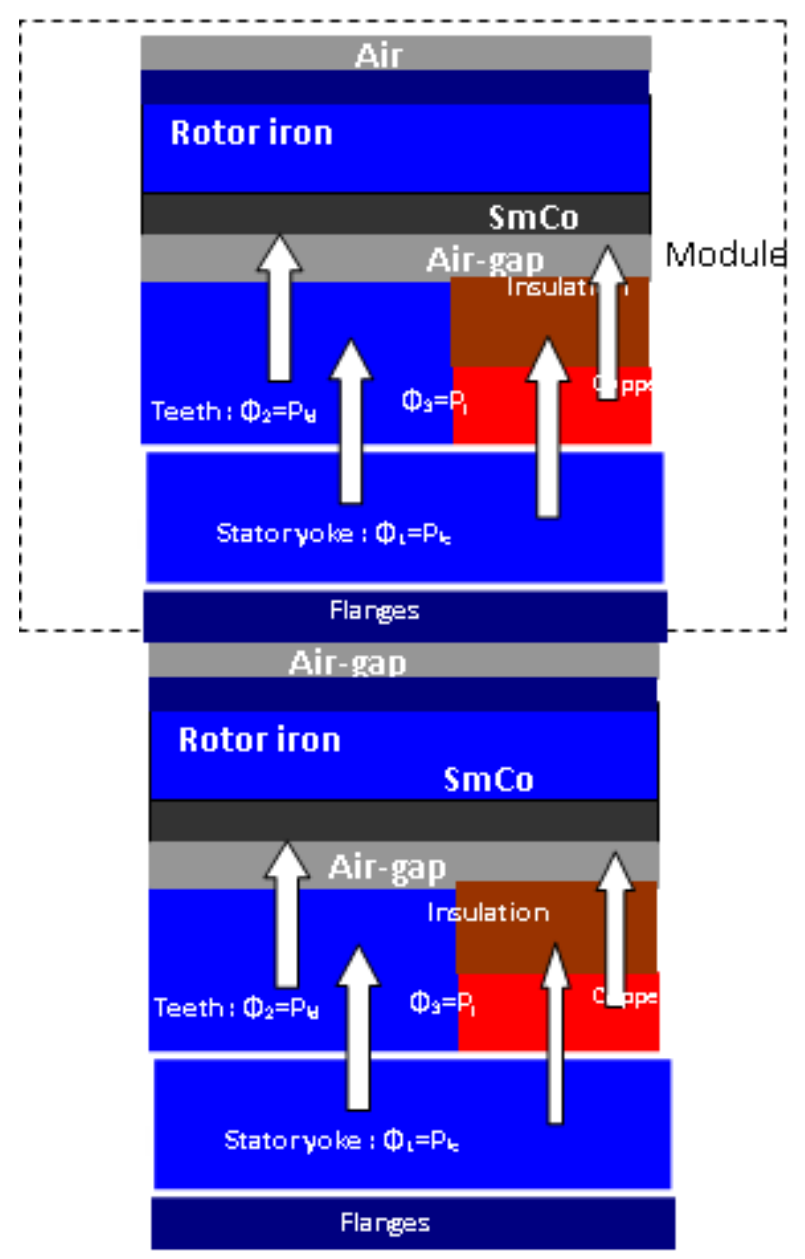

Figure 3. The heat transfer in the PMSM.

\section{Transient Thermal Model}

We selected a model using thermal-electrical analogy. In order to simplify the model, we have the following assumptions:

- Uniform heat generation.

- Uniformity of physical properties across the element.

- Uniformity of the exchanges on each of the faces.

The machine is divided into simple volume elements exchanging heat between them by conduction or convection. Copper losses include slots losses and end winding losses. The transient thermal model of the PMSM structure can then be represented by an analog electrical network, as described in figure 4 [8], [9], [10]. 


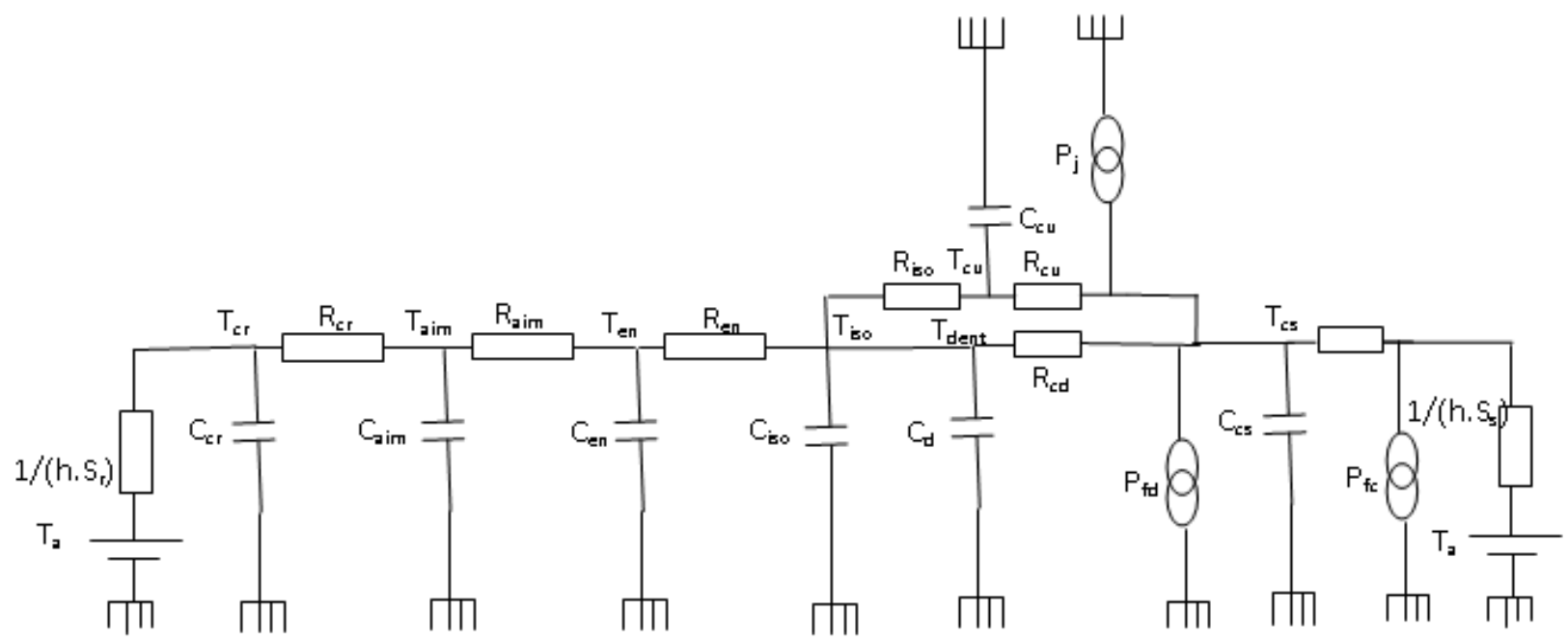

Figure 4. Transient thermal model of the PMSM actuator.

Table 1 illustrates the nomenclature of the nodal model diagram:

Table 1. Nomenclature of the nodal model diagram.

\begin{tabular}{ll}
\hline $\mathbf{h}$ & Convection coefficient \\
\hline $\mathrm{S}_{\mathrm{r}}$ & Active section of the rotor \\
$\mathrm{h}_{\mathrm{f}}$ & Forced convection coefficient \\
$\mathrm{S}_{\mathrm{s}}$ & Active section of the stator \\
$\mathrm{R}_{\mathrm{cr}}$ & Rotor yoke conduction resistance \\
$\mathrm{R}_{\mathrm{aim}}$ & Magnets conduction resistance \\
$\mathrm{R}_{\mathrm{en}}$ & Air-gap conduction resistance \\
$\mathrm{R}_{\mathrm{cu}}$ & Copper conduction resistance \\
$\mathrm{R}_{\mathrm{cd}}$ & Teeth conduction resistance \\
$\mathrm{R}_{\mathrm{cs}}$ & Stator yoke conduction resistance \\
$\mathrm{P}_{\mathrm{j}}$ & Copper losses \\
$\mathrm{P}_{\mathrm{fd}}$ & Teeth iron losses \\
$\mathrm{P}_{\mathrm{fc}}$ & Stator yoke iron losses \\
$\mathrm{T}_{\mathrm{a}}$ & Ambient temperature \\
$\mathrm{T}_{\mathrm{cr}}$ & Rotor yoke temperature \\
$\mathrm{T}_{\mathrm{aim}}$ & Magnets temperature \\
$\mathrm{T}_{\mathrm{en}}$ & Air-gap temperature \\
$\mathrm{T}_{\mathrm{cu}}$ & Copper temperature \\
$\mathrm{T}_{\mathrm{iso}}$ & Average temperature of the insulation \\
$\mathrm{T}_{\mathrm{dent}}$ & Teeth temperature \\
$\mathrm{T}_{\mathrm{cs}}$ & Stator yoke temperature \\
$\mathrm{C}_{\mathrm{cr}}$ & Thermal capacity of the rotor yoke \\
$\mathrm{C}_{\mathrm{aim}}$ & Thermal capacity of magnets \\
$\mathrm{C}_{\mathrm{en}}$ & Thermal capacity of the air-gap \\
$\mathrm{C}_{\mathrm{cu}}$ & Thermal capacity of the copper \\
$\mathrm{C}_{\mathrm{iso}}$ & Thermal capacity of the insulation \\
$\mathrm{C}_{\mathrm{d}}$ & \\
$\mathrm{C}_{\mathrm{cs}}$ & \\
&
\end{tabular}

For the model presented in figure 4, we define two isothermal zones constituted by the magnetic material on the one hand and by the winding on the other hand.

Previously defined areas are warm seat due to copper losses and iron losses.

$\mathrm{P}_{\mathrm{j}}, \mathrm{P}_{\mathrm{fc}}$ and $\mathrm{P}_{\mathrm{fd}}$ corresponding respectively to the total copper losses in the coils and iron losses of the yoke and stator teeth. The variables Ti correspond to the temperatures at different points of the machine. The terms of thermal resistances are deduced from the resolution of the heat equation border areas.

\subsection{Calculation of Conduction Resistances}

For the sake of simplification, the conduction along the transverse axis of the stator is not taken although it may be essential, especially in the windings. Heat transfer in a stator element therefore allows one preferred direction, the axial direction. This is reflected by the following heat equation [10].

$$
\frac{\overrightarrow{\Phi_{T}}}{S_{e t}}=-\lambda \times \overrightarrow{\operatorname{grad}} T=-\lambda \times \frac{T_{1}-T_{2}}{x_{1}-x_{2}} \vec{x}
$$

Equation 2 can be derived from a general formula of thermal conduction resistance to an axial flux distribution:

$$
R=\frac{E}{\lambda \times S_{e t}}
$$

Where $\lambda$ is the thermal conductivity, $S_{\text {et }}$ is the heat exchange section and $\Phi_{\mathrm{T}}$ is the total heat flux exchanged and $\mathrm{E}$ is the thickness of the heat exchange.

The conduction resistances can be deduced from the geometrical equations of PMSM [7].

For PMSM structures, the conduction resistances of the materials constituting the rotor are expressed by the following relationships:

The conduction resistance of the rotor yoke is expressed by the following relationship:

$$
R_{c r}=\frac{H_{c r}}{\lambda_{f e r} \times\left(\pi \times \frac{D_{e}^{2}-D_{i}^{2}}{4}\right)}
$$

Where $\lambda_{\text {fer }}$ is the thermal conductivity of the iron, $\mathrm{H}_{\mathrm{cr}}$ is the rotor yoke thikness, $\mathrm{D}_{\mathrm{e}}$ and $\mathrm{D}_{\mathrm{i}}$ are respectively the exetrnel and internal diameter of the motor.

The conduction resistance of the magnet is expressed by the following relationship: 


$$
R_{\text {aim }}=\frac{H_{a}}{\lambda_{a} \times 2 \times p \times S_{a}}
$$

Where $\lambda_{\mathrm{a}}$ is thermal conductivity of the magnets, $\mathrm{p}$ is the nomber of pole pairs, $\mathrm{S}_{\mathrm{a}}$ is the magnet section and $\mathrm{H}_{\mathrm{a}}$ is magnet thikness.

The conduction resistance of the air-gap is expressed by the following relationship:

$$
R_{e n}=\frac{e}{\lambda_{\text {air }} \times\left(\pi \times \frac{D_{e}^{2}-D_{i}^{2}}{4}\right)}
$$

Where $\lambda_{\text {air }}$ is the thermal conductivity of air and $e$ is the air-gap thikness.

The conduction resistances respectively of the coils $\left(R_{c u}\right)$, insulation $\left(\mathrm{R}_{\mathrm{iso}}\right)$ of main teeth $\left(\mathrm{R}_{\mathrm{cd}}\right)$ and stator yoke $\left(\mathrm{R}_{\mathrm{cs})}\right.$ for the two structures are equal.

The conduction resistance of the coils is expressed by the following relationship:

$$
R_{c u}=\frac{K_{f} \times H_{d}}{\lambda_{c} \times N_{d} \times\left(2 \times L_{e n c} \times \frac{D_{e}-D_{i}}{2}+\frac{D_{i}}{2} \times A_{\text {dent } 1} \times L_{e n c}+\frac{D_{e}}{2} \times A_{\text {dent } 2} \times L_{e n c}\right)}
$$

Where $\lambda_{c}$ is the thermal conductivity of copper and $H_{d}$ is the stator tooth high.
The conduction resistance of the insulator is expressed by the following relationship:

$$
R_{i s o}=\frac{\left(1-K_{f}\right) \times H_{d}}{\lambda_{i s o} \times N_{d} \times\left(2 \times L_{e n c} \times \frac{D_{e}-D_{i}}{2}+\frac{D_{i}}{2} \times A_{\text {dent } 1} \times L_{e n c}+\frac{D_{e}}{2} \times A_{d e n t 2} \times L_{e n c}\right)}
$$

Where $\lambda_{\text {iso }}$ is the thermal conductivity of the insulation, $A_{\text {dent1 }}$ the lower main tooth angle, $A_{\text {dent2 }}$ is higher angle of the main tooth, $\mathrm{N}_{\mathrm{d}}$ is the tooth number.

The slot width $\mathrm{L}_{\mathrm{enc}}$ is expressed as follows:

$$
L_{e n c}=B \sin \left(\frac{1}{2}\left(\frac{2 \pi}{N_{d}}-\alpha \beta \frac{\pi}{p}\left(1-r_{d i d}\right)\right)\right)
$$

Where $r_{\text {did }}$ is the ratio between the angular width of the inserted tooth and that of the principal tooth. This ratio is optimised by finite elements simulations in order to reduce the flux leakages and to improve the back electromotiv force wave-form.

Where $\mathrm{B}$ is equal to:

$$
B=\frac{D_{e}+D_{i}}{2}
$$

The PMSM configuration is caracterized by variation law of the pole pairs number ( $p$ ) according to an integer number $n$ varying from one to infinity, the ratio $(r)$ of the number of principal teeth $\left(\mathrm{N}_{\mathrm{d}}\right)$ by the number of pole pairs, the ratio $(\mathrm{v})$ between the angular width between two principal teeth and that of a principal tooth, the ratio $(\alpha)$ between the angular width of a principal tooth and that of a magnet and the ratio $(\beta)$ between the angular width of a magnet and the polar step.

The conduction resistance of the main teeth is expressed by the following relationship:

$$
R_{c d}=\frac{H_{d}}{\lambda_{f e r} \times\left(N_{d} \times S_{d}\right)}
$$

Where $H_{d}$ is the teeth high, $S_{d}$ is the main tooth section.
The conduction resistance of the stator yoke is expressed by the following relationship:

$$
R_{c s}=\frac{H_{c s}}{\lambda_{f e r} \times\left(\pi \times \frac{D_{e}^{2}-D_{i}^{2}}{4}\right)}
$$

Wher $\mathrm{H}_{\mathrm{cs}}$ is the stator yoke thikness.

\subsection{Convection Resistances Computation}

The convective heat transfer is the preferred mode of transfer within the fluids. Then it is generally much more important than conduction. We must distinguish between natural convection and forced convection.

Density differences related to differences in temperature cause movements of the fluid which is heated in contact with hot body and thus carries the heat to colder areas: the natural convection. The yoke and the outer flanges of the machine in the absence of external fan, undergo this transfer mode. In the internal parts, not brewed areas are rare due to the rotor [10]. The heat exchange coefficient between the housing and the ambient air, can be between 20 and $50 \mathrm{~W} . \mathrm{K}^{-1} \cdot \mathrm{m}^{-2}$ for machine natural ventilation and can exceed $80 \mathrm{~W} \cdot \mathrm{K}^{-1} \cdot \mathrm{m}^{-2}$ for machines with forced ventilation [9], [10].

The only network element that refers to a transfer by convection is $R_{\text {ext }}$, which represents the overall thermal resistance between the surface of the casing, the flanges and the ambient air.

$$
\mathrm{R}_{\mathrm{ex}}=\frac{1}{\mathrm{~h} \cdot \mathrm{S} \mathrm{s}}=\frac{1}{\mathrm{~h} \cdot \mathrm{S} \mathrm{r}}
$$

Where $\mathrm{h}$ is the heat transfer coefficient, $\mathrm{S}_{\mathrm{s}}$ is the area of heat 
exchange with the stator and $\mathrm{S}_{\mathrm{r}}$ is the area of heat exchange with the rotor.

The calculation of external surface of the actuator requires some remarks. Should we consider only the side surfaces (flanges) of the machine or also include the outer surface of the cylinder? Model assumptions, namely a consideration of phenomena only in the axial axis, incite choose the first solution. Wherein the surfaces of heat exchange by convection are expressed by the following relationship:

$$
S_{s}=S_{r}=\pi \times \frac{D_{e}^{2}}{4}
$$

\subsection{Calculation of Thermal Capacity}

We will study the thermal phenomena of a transient point of view, it is therefore necessary to involve the heat capacities of the materials constituting the components of the machine.

The terms of thermal capacity is calculated from the following relationship between the mass of materials and their massive heat capacity using the following equation [9], [10]:

$$
C=\rho \times V \times c=M \times c
$$

With $\rho$ is the density of the material, $\mathrm{V}$ is the volume of the material, $\mathrm{c}$ is the mass heat capacity of the material and $\mathrm{M}$ is the mass of the material.

\subsection{Heat Flux}

The heat flux $\Phi_{1}$ corresponds to iron losses in the stator yoke $\left(\mathrm{P}_{\mathrm{fc}}\right)$. This flux propagates from the center of gravity of the stator yoke. It is expressed by the following equation [7]:

$$
\Phi_{1}=P_{f c}=q \times f^{1.5} \times M_{c s} \times B_{c s}^{2}
$$

Where $\mathrm{q}$ is the quality factor of the metal sheets, $\mathrm{M}_{\mathrm{cs}}$ is the mass of the stator yoke and $\mathrm{B}_{\mathrm{cs}}$ is the magnetic induction in the stator yoke.

The heat flux $\Phi_{2}$ corresponds to the iron losses in the stator yoke $\left(\mathrm{P}_{\mathrm{fd}}\right)$. This flux propagates from the center of gravity of the stator teeth. It is expressed by the following equation [7]:

$$
\Phi_{2}=P_{f d}=q \times f^{1.5} \times M_{d s} \times B_{d}^{2}
$$

Where $M_{d s}$ is the mass of the stator teeth and $B_{d}$ is the magnetic induction in the stator teeth.

The heat flux $\Phi_{3}$ corresponds to the copper losses in the stator $\left(\mathrm{P}_{\mathrm{j}}\right)$. This flux propagates from the center of gravity of the stator copper. It is expressed by the following equation:

$$
\Phi_{3}=P_{j}=\frac{3}{2} \times R \times I^{2}
$$

Where $\mathrm{R}$ is the resistance of the stator winding, it is expressed by the following relationship:

$$
R=\frac{r_{c u} \times N_{s} \times L_{s p}}{\frac{C_{\mathrm{dim}}}{\sqrt{2} \times \delta \times K_{e}}}
$$

Where $r_{c u}$ is the resistivity of copper, $L_{s p}$ is the average length of one turn, $\mathrm{N}_{\mathrm{s}}$ is the number of phase spires, $\mathrm{C}_{\mathrm{dim}}$ is the dimensionnig torque of the motor, $\delta$ is the current density in the copper and $\mathrm{K}_{\mathrm{e}}$ is the back electromotive force constant.

$$
L_{s p}=\left(A_{\text {dent } 1}+A_{e n c 1}\right) \times\left(\frac{D_{i}}{2}-\frac{L_{e n c}}{2}\right)+\left(A_{\text {dent } 2}+A_{e n c 2}\right) \times\left(\frac{D_{e}}{2}-\frac{L_{e n c}}{2}\right)+2 \times\left(\left(\frac{D_{e}-D_{i}}{2}\right)+L_{e n c}\right)
$$

\section{Simulation Results}

The loss model for PMSM for an electromagnetic switch power chain is located under the environment of Matlab / Simulink 7.1 version. Heat fluxes are calculated based on the inverse modeling approach of the power chain (figure 5).

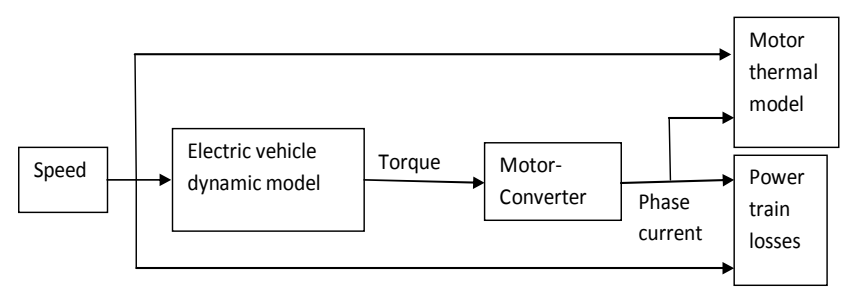

Figure 5. Electric vehicle power train model.

Simulation results are obtained for the standard travels (1027 s) during repeated sequences.

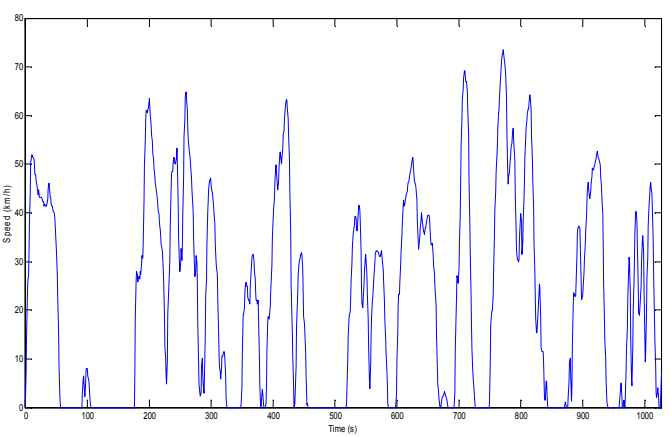

Figure 6. Standardized travels.

The simulation of the thermal model of the PMSM structure, with natural convection with air (convection coefficient equal to $\left.30 \mathrm{~W} /\left(\mathrm{m}^{2} . \mathrm{K}\right)\right)$, shows the evolution of temperatures in different active parts of the motor (figure 7). 


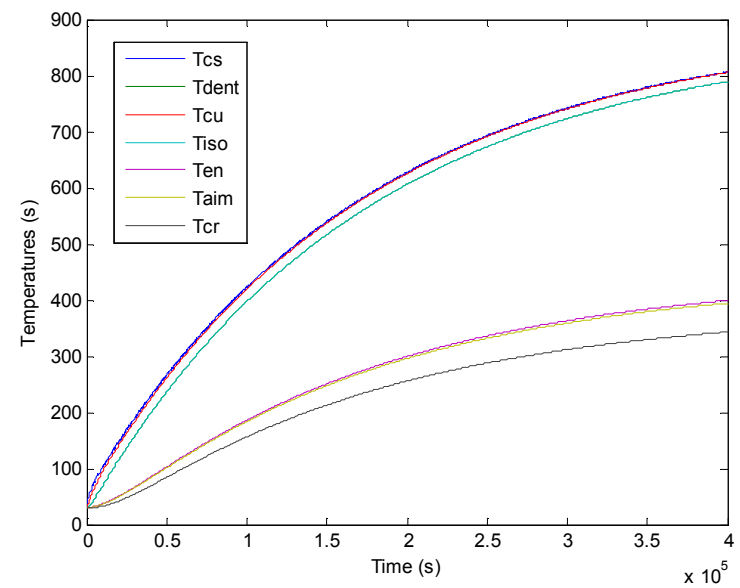

Figure 7. Evolution of temperatures in the different active parts of the motor $\left(h=30 \mathrm{~W} /\left(\mathrm{m}^{2} \cdot \mathrm{K}\right)\right)$.

Where Tcr is the average temperature of the rotor yoke, Taim is the average temperature of magnets, Ten is the average temperature of the air gap, Tiso is the average temperature of the insulation, Tcu is the average temperature of the copper, Tdent is the average temperature of the stator teeth and Tcs is the average temperature of the stator yoke.

This figure shows that there's an exceeding of $700^{\circ} \mathrm{C}$ for the the insulation, which proves the need for a cooling system. Several simulations are undertaken for several values of forced convection coefficient in water, have led to the fixing of the this coefficient to $5000 \mathrm{~W} /\left(\mathrm{m}^{2} . \mathrm{K}\right)$.

Evolutions of temperature in the different active parts of the engine for operation with a cooling system with forced convection in water $\mathrm{h}=5000 \mathrm{~W} /\left(\mathrm{m}^{2} . \mathrm{K}\right)$ is illustrated in figure 8.

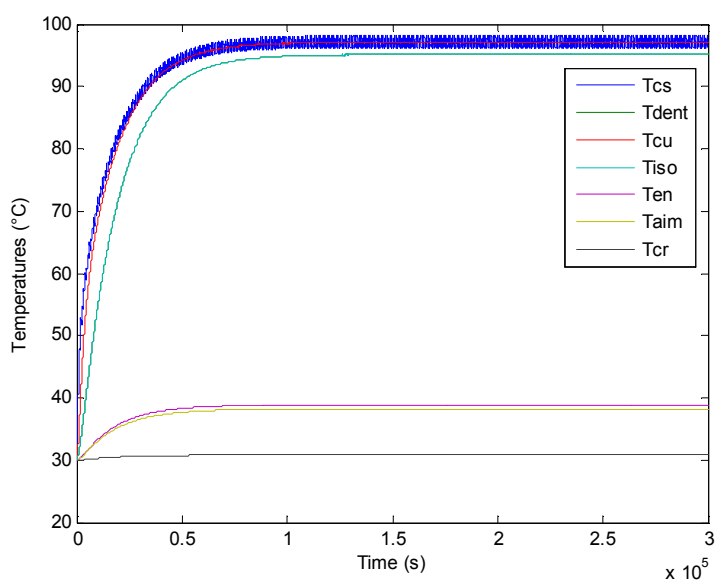

Figure 8. Evolution of temperatures in the different active parts of the motor $\left(h=5000 \mathrm{~W} /\left(\mathrm{m}^{2} \cdot \mathrm{K}\right)\right)$.

This figure shows that the temperature of the insulation is reduced to $90^{\circ} \mathrm{C}$, acceptable value.

\section{Conclusion}

In this paper we present a methodology for electrothermal modeling of PMSM configuration to define the less powerful and the least expensive cooling system. This approach is based on modeling with nodal method because it provides a fast and acceptable precision for our application. It is compatible to optimization approaches of the design parameters of electric cars. This study led to the selection of a cooling system by water forced convection. Finally, the approach of thermal modeling tool presents a thermal characterization of the PMSM dedicated to the design of these types of actuators. It will be interesting as future work to address the phase of experimental validation of the model presented in this paper.

\section{References}

[1] M.N. Ajour, L.A. Dissado, J.C. Fothergill, P.N. Norman, "Dielectric spectroscopy of Epoxy/Glass composite materials", Conference on Electrical Insulation and Dielectric Phenomena, (2002), pp.438-441,

[2] A. Apicella, L. Egiziano, L. Nicolais and V. Tucci, "Environmental degradation of the electrical and thermal properties of organic insulating materials", Journal of materials science, (1988), vol.23, p. 729-735

[3] TOUNSI et R. NEJI: «Design of an Axial Flux Brushless DC Motor with Concentrated Winding for Electric Vehicles», Journal of Electrical Engineering (JEE), Volume 10, 2010 Edition: 2, pp. 134-146.

[4] A. AMMOUS, B. ALLARD, H. MOREL: «Transient temperature mesurements and modeling of IGBT's under short circuit», IEEE transaction electronic devices, vol. $13, \mathrm{n}^{\circ} 1$, 1998, p. 12-25.

[5] P. H. Mellor, D. Roberts, D. R Turner. «Lumped Parameter Thermal Model for Electrical machine of TEFC design». IEEE Trans on Electrical Power Application., 1991, 138(5): 205-2018.

[6] Gerling D, Dajaku G. Novel «lumped-parameter thermal model for electrical systems» Power Electronics and Applications, 2005 European Conference on. IEEE, 2005: 10 pp.-P. 10.

[7] S.TOUNSI, R.NÉJI, F.SELLAMI : « Conception d'un actionneur à aimants permanents pour véhicules électriques ", Revue Internationale de Génie Électrique volume 9/6 2006 pp.693-718.

[8] Staton D, Boglietti A, Cavagnino A. «Solving the more difficult aspects of electric motor thermal analysis in small and medium size industrial induction motors». Energy conversion, IEEE transactions on, 2005, 20(3): 620-628.

[9] Sun Xikai, Cheng Ming. «Thermal analysis and cooling system design of dual mechanical port machine for wind power application». IEEE Transactions on Industrial Electronics, May 2013, 60(5): 1724-1733.

[10] Zhu Sa, Cheng Ming. «Core loss analysis and calculation of stator permanent magnet machine considering dc-biased magnetic induction». IEEE Transactions on Industrial Electronics. Digital Object Identifier: 10.1109/TIE.2014.2300062. 